\title{
GCU
}

Glasgow Caledonian

University

University for the Common Good

\section{Public views on principles for health care priority setting: findings of a European cross-country study using $\mathbf{Q}$ methodology}

van Exel, Job; Baker, Rachel; Mason, Helen; Donaldson, Cam; Brouwer, Werner; EuroVaQ Team

Published in:

Social Science and Medicine

DOI:

10.1016/j.socscimed.2014.12.023

Publication date:

2015

Document Version

Author accepted manuscript

Link to publication in ResearchOnline

Citation for published version (Harvard):

van Exel, J, Baker, R, Mason, H, Donaldson, C, Brouwer, W \& EuroVaQ Team 2015, 'Public views on principles for health care priority setting: findings of a European cross-country study using Q methodology', Social Science and Medicine, vol. 126, pp. 128-137. https://doi.org/10.1016/j.socscimed.2014.12.023

\section{General rights}

Copyright and moral rights for the publications made accessible in the public portal are retained by the authors and/or other copyright owners and it is a condition of accessing publications that users recognise and abide by the legal requirements associated with these rights.

Take down policy

If you believe that this document breaches copyright please view our takedown policy at https://edshare.gcu.ac.uk/id/eprint/5179 for details

of how to contact us. 
Public views on principles for health care priority setting: findings of a European cross-country study using Q methodology

Job van Exel ${ }^{a,{ }^{*}}$, Rachel Baker ${ }^{b}$, Helen Mason ${ }^{b}$, Cam Donaldson ${ }^{b}$, Werner Brouwer ${ }^{a}$ and the EuroVaQ Team

${ }^{\text {a }}$ Erasmus University Rotterdam, Institute of Health Policy and Management, Rotterdam, the Netherlands

${ }^{b}$ Yunus Centre for Social Business and Health, Glasgow Caledonian University, Glasgow, G4 OBA, Scotland

Address for correspondence

Erasmus University Rotterdam, Institute of Health Policy and Management (iBMG)

a/o Job van Exel, office J5-39

PO Box 1738

3000 DR Rotterdam

The Netherlands

E: vanexel@bmg.eur.nl

$\mathrm{T}:+31(0) 104082507$

F: $+31(0) 104089094$ 


\section{Abstract}

Resources available to the health care sector are finite and typically insufficient to fulfil all the demands for health care in the population. Decisions must be made about which treatments to provide. Relatively little is known about the views of the general public regarding the principles that should guide such decisions.

We present the findings of a $Q$ methodology study designed to elicit the shared views in the general public across ten countries regarding the appropriate principles for prioritising health care resources. In 2010, 294 respondents rank ordered a set of cards and the results of these were subject to by-person factor analysis to identify common patterns in sorting. Five distinct viewpoints were identified, (I) "Egalitarianism, entitlement and equality of access"; (II) "Severity and the magnitude of health gains"; (III) "Fair innings, young people and maximising health benefits"; (IV) "The intrinsic value of life and healthy living"; (V) "Quality of life is more important than simply staying alive".

Given the plurality of views on the principles for health care priority setting, no single equity principle can be used to underpin health care priority setting. Hence, the process of decision making becomes more important, in which, arguably, these multiple perspectives in society should be somehow reflected. 


\section{Highlights}

- Little is known about views in society on principles to guide priority setting.

- We used Q methodology with members of the public across ten countries.

- We found five shared views on principles regarded appropriate for rationing.

- No single equity principle can be used to underpin priority setting in health care.

- This plurality of views in society should be reflected in priority setting processes.

\section{Keywords}

- Europe

- Resource allocation

- Decision making

- Health care

- Social values

- Q methodology

- Qalys

- Equity 


\section{Introduction}

Resources available to the health care sector are ultimately finite and typically insufficient to fulfil all the demands and needs for health care in the population. Although this truth may be inconvenient and, in some countries, may even be contested (e.g. Greiner and Von der Schulenburg, 2010), choices in the allocation of health care resources are, in essence, unavoidable. This means that decisions have to be made about which treatments are provided (and which patients will be helped), and which treatments are not provided (and which patients will be denied help). The contexts and ways in which such decisions are made differ between health care systems and sectors within health care. For instance, at the macro- or health care system level, it may be necessary to decide which drugs and other technologies to reimburse. At the meso- or hospital level, it may be necessary to set up rules for whom to treat first when there are waiting lists for particular services. At the micro or patient group level, it may be necessary to set a specific threshold for risk levels for health problems beyond which to start treatment (e.g. in case of high cholesterol). All such (explicit and implicit) choices are of course related and have implications for the final allocation of resources in the health care sector (Klein, 1993; Litva et al., 2002). The obvious question then is, on what basis such choices should be made? This question can provoke heated debate in the context of explicit priority setting (or rationing) as it involves difficult trade-offs and intrinsically normative questions regarding the aim(s) and value(s) of the health care sector. Typically, the aim of the health care sector will involve notions of efficiency and equity (Dolan et al., 2005). Ideally, therefore, allocation decisions reflect these two, potentially conflicting, notions. 
The tension between equity and efficiency in the health care sector is apparent in a range of routine decisions and practices. For instance, in the prioritisation of patients on a waiting list, the aim to maximize overall health benefits from treatment may be at conflict with that of obtaining an equitable distribution of health and health care. As an illustration, a proposal in the Netherlands to treat employees more quickly than non-employees by creating additional treatment capacity, thus reducing waiting times for all (though unequally so) and saving lost production due to absence, was rejected. The main reason was that it was considered to be inequitable to treat employees quicker than non-employees, while their medical need (or capacity to benefit) was not necessarily higher (Brouwer \& Schut, 1999). A similar tension may be observed in the controversy around user fees in the health care sector. While such fees may help to raise cost-consciousness and reduce moral hazard, they may also result in socio-economic differences in access to health care (Donaldson \& Gerard, 1989).

Efficiency and equity are also central to debates regarding appropriate decision rules for reimbursement of new health technologies based on economic evaluations. A commonly applied decision rule is to assess whether the additional health benefits in terms of qualityadjusted life-years (QALYS) are 'worth' the additional costs. If the cost per QALY is below some (agreed upon) threshold, the treatment is taken to represent value for money and thus deemed eligible for funding. An important and much discussed question, however, is whether all QALYS should have equal value in these decisions (Bobinac et al., 2012; Brouwer et al., 2008; Dolan et al, 2005; Gerard \& Mooney, 1993; Donaldson et al., 1988; Weinstein, 1988). Much empirical evidence suggests that people do not attach equal value (or weight) to different QALYs benefiting different groups of people. For instance, a QALY gained by a 
severely ill person may be valued (weighted) differently than a QALY gained in a person who is only mildly ill - the 'severity of illness' argument - and more so in a young person than in an old person - the 'fair innings argument' (Williams, 1997, 1988a; Nord, 2005; Donaldson et al., 2011; 1988). The relevance of equity considerations is also evident in policy debates regarding the valuation of benefits of end-of-life care and the treatment of 'rare' diseases. In the UK, recently, some room has been created to accommodate these equity considerations in the decision making process, by allowing specific life prolonging interventions to be judged against a higher cost per QALY threshold (National Institute for Health and Clinical Excellence, 2009; Longson and Littlejohns, 2009; Scottish Medicines Consortium, 2010); it is however uncertain whether these measures reflect actual societal values (Linley \& Hughes, 2013). In the Netherlands, as a general rule, higher thresholds are allowed for interventions aimed at increasingly severe illnesses (College voor Zorgverzekeringen, 2006; Van de Wetering et al., 2013).

If policy makers wish to reflect, or at least be responsive to, equity considerations or more general views on appropriate allocation of health care resources among the general public, more knowledge on such public preferences is necessary. However, robust research evidence reflecting the richness of the viewpoints among the public regarding the distribution of health and health care, is lacking (Buxton et al., 2011; Donaldson et al., 2011). A number of studies have investigated public preferences, but they have typically focussed on specific treatments or patient groups, whilst a number of literature reviews have shown a wide variety of equity considerations and attitudes towards distribution of health care (van de Wetering et al., 2013; Bobinac et al., 2012; Schwappach, 2005; Dolan et al., 2005; Tsuchiya \& Dolan, 2005; Smith \& Richardson, 2005). In-depth studies of public opinions 
regarding the relative value of health gains and incorporating the full range of relevant issues are rare; the recent social value of a QALY (SVQ) project in the UK is a notable example (Lancsar et al. 2011; Baker et al., 2014).

The current study was part of the 'European Value of a Quality adjusted life year' (EuroVaQ) project (Donaldson et al., 2010), conducted in ten countries: Denmark, France, Hungary, Norway, Palestine, Poland, Spain, Sweden, the Netherlands and the UK. One of the principle aims of EuroVaQ was to develop and test robust methods to determine the monetary value of a QALY (Robinson et al., 2013; Pennington et al., 2013). The aim of study presented here was to describe the shared views in the general population across these ten countries regarding the prioritisation of health care.

Q methodology combines qualitative and quantitative methods and provides a scientific foundation for the systematic study of subjectivity (Stephenson, 1935; Brown, 1980; Watts \& Stenner, 2012; McKeown \& Thomas, 2013). Although the origins of Q methodology are in psychology, it is now relatively well established in health services research, with a rapidly growing number of published studies on a variety of health related topics: for instance, health behaviour and outcomes (Baker, 2006; Stenner et al., 2003), attitudes and beliefs (Vermaire et al., 2010; Van Exel et al., 2006; Eccleston et al., 1997), treatment adherence (Cramm et al., 2010; Tielen et al., 2008), coping and adaptation (Kraijo et al., 2012; Boot et al., 2009; Risdon et al., 2003), and professional views (Lobo et al., 2012; Wallenburg et al., 2010; Buljac et al., 2010).

In a $Q$ methodology study respondents rank a set of opinion statements through a card sorting procedure known as a ' $Q$ sort', and by doing so reveal their point of view toward the subject being studied. The rankings of the respondents are subject to correlation analysis, 
and the correlation between individual rankings is taken to indicate similarity between viewpoints. By-person factor analysis (Kline, 1994) is then used to identify significant clusters of correlations, which can be interpreted as distinguishable viewpoints. Q methodology is thus used to describe a 'population of viewpoints' and the correspondence and distinctions between them. By its nature - and in contrast to survey research - Q relies on relatively small purposive respondent samples (i.e., typically 25 to 40 respondents) conducting a large number of 'tests' (i.e., a full ranking of 30 to 50 statements). An important consequence is that, like qualitative findings, the results of a $Q$ study may be generalised to the subject area from which the opinion statements were sampled, but not - as in survey research - to the population (Brown, 1980; Watts \& Stenner, 2012). In other words, logical generalisations can be drawn about the nature of opinion and shared perspectives that exist on a given topic (here priority setting in health) but nothing can be said about how many people are associated with each viewpoint identified, or about their likely characteristics.

McKeown and Thomas (2013), Watts and Stenner (2012) and De Graaf and van Exel (2009), among others, provide comprehensive introductions to Q methodology. Brown et al. (2014) recently discussed some of the main critiques of Q methodology.

\section{Methods}

Our study was conducted in three steps, as common to $Q$ methodology studies. The first step was developing a ' $Q$ set' of items (here statements of opinion regarding priority setting in health care) for respondents to rank order. The second step was identifying participants 
and administering the Q-sort interviews. The third step was analysis and interpretation. These steps are described more in detail below.

\section{Step 1: Collection of opinion statements and selection of statement set}

The $Q$ set should be representative of the 'universe of opinions' on the topic in question, in this case, opinions regarding priority setting in health care. In order to develop such a comprehensive list of statements covering all issues that the general public may possibly want to take into account in health care priority setting, a review of the literature on the social value of a QALY was conducted taking four fairly recent, related reviews as starting point (Schwappach, 2002; Dolan, Shaw \& Tsuchiya, 2005; Tsuchiya \& Dolan, 2005; Smith \& Richardson, 2005). In the review we undertook (Bobinac et al., 2012), issues were identified that the general public may want to take into account in health care priority setting. A rough long-list of such issues was compiled and categorised by a team of five researchers. Health economists from the ten countries participating in the EuroVaQ study reviewed this categorized list to ensure that it reflected the full range of 'egalitarian' to 'libertarian' issues (Donabedian, 1971) and current policy issues in their country. A set of 23 potentially relevant issues for prioritisation of health care, concerning characteristics of patients, illnesses, treatments and health and non-health effects of treatment (see Annex A), was agreed and adopted as the theoretical structure for the development of a representative set of opinion statements.

Based on this theoretical structure, the literature review and previous qualitative and Q methodology research by some of the authors (Baker et al., 2010), two researchers drafted a list of opinion statements. In order to achieve balance, as well as coverage (Watts 
\& Stenner, 2012) at least two opinion statements were selected for each issue. This resulted in 80 candidate statements. Five researchers discussed and refined these statements (deleting duplicates, merging similar statements), and condensed the long-list to a $Q$ set of 37 opinion statements. Piloting of the $Q$ set was conducted in three phases. First, a panel of health economists, other academic staff and non-academic staff $(n=15)$ commented on the statements and the clarity of language for a lay sample of respondents. Second, health economists $(n=26)$ from the ten countries participating in the EuroVaQ study reviewed the materials by ranking the $Q$ set using the draft interview materials. In addition, the materials were translated from English into the other nine languages by partners in the EuroVaQ study from each country, back-translated by their colleagues to check correct translation; and differences in meaning were resolved. Finally, pilot tests were organised with convenience samples of members of the general public in the Netherlands and the UK and with members of the international $Q$ methodology association (www.qmethod.org). Based on the piloting, some statements were reworded, and three further statements were removed because they were considered unintelligible (1) or too similar to other statements (2). This resulted in a final set of 34 opinion statements, which are presented in Table 1. The statements were allocated a number between 1 and 34 at random and printed onto cards.

\section{Step 2: Administration of $Q$ sorts}

Respondent sampling in Q methodology is similar to purposive, qualitative sampling: the aim being to elicit the views of respondents who are likely to have different perspectives. Researchers from the 10 countries participating in this study recruited respondents locally, following specific instructions. A sampling frame was designed to identify respondents from 
the general public who were likely to differ in their views about priority setting in health. We had little prior knowledge of characteristics that were likely to affect such views, but based on the theoretical structure underlying the statement set (Annex A) we anticipated that age, having dependent adults or children, socio-economic and health status may be relevant. For each country, the local EuroVaQ partner was asked to recruit between twenty and thirty respondents (for in person and online interviews, respectively) stratified by gender (as a common confounder) and three age/offspring groups: 18 to 25 (no children); 25 to 65; 65 and older. In order to keep the sampling frame and the recruitment of participants across ten countries relatively simple we decided to restrict the youngest age group to people with no children, while not imposing any restriction vis-à-vis children in the two other age groups. In addition, partners were asked to recruit respondents with varying socio-economic and health status across the whole sample. Data about socio-economic and health status of respondents were collected after conclusion of the $Q$ sort interview.

Most partners (i.e. Denmark, France, Norway, Palestine, Poland, Spain, Sweden and the Netherlands) followed the suggested strategy and recruited a convenience sample by asking friends or colleagues to suggest candidate respondents matching the characteristics of the sampling framework, and consecutively approaching those people until the required number of interviews was reached. Other partners recruited through advertisement in a newspaper (i.e. Hungary) or using a recruitment company (i.e. the UK). Data was collected in 2010.

Materials were designed such that $\mathrm{Q}$ sorts could be administered in person or online. A repeated in person and online interview pilot study ( $n=20$; two-weeks apart) showed that the comparability of results from both modes of administration was good $(\rho=0.8)$. All 
respondents were given similar guidance on the completion of the card sorting exercise (see Annex $\mathrm{B}$ ), beginning by sorting the cards according to their opinion about how health care decisions should be made in their country, into one of three piles: agree, disagree and neutral. Next, they were directed to place the cards from the three piles onto a sorting grid (see Figure 1) which ranged from most agree to most disagree; in doing so drawing finer distinctions between them. Finally, after completing the $Q$ sort, respondents were asked to clarify their views by explaining their reasons for placing the two statements at the extreme ends (i.e., in column 1 or 9) of the sorting grid.

A minimum response time of 10 minutes was set for completing the $Q$ sort online, based on the results of a pilot study (The online $Q$ sort interview is available at: www.qmethodology.net/eurovaq/index.html). No minimum duration was set for the in person interviews.

[Figure 1 about here]

The positioning of statements in each $Q$ sort was coded from - 4 for the statements placed in column 1 to +4 for those placed in column 9 of the sorting grid.

\section{Step 3: Analysis and interpretation of $Q$ sorts}

The data collected in 10 countries were pooled, as the aim was to identify general views shared across the countries of study. The data were analysed using the dedicated software package PQMethod (Schmolck \& Atkinson, 2002). By-person factor analysis (i.e. centroid 
factor analysis followed by varimax rotation) was conducted to identify clusters of respondents whose Q sorts were highly correlated.

All factor solutions supported by the data were computed and inspected. First, an idealised $Q$ sort was generated for each factor in each factor solution, which represents the way in which a person with a correlation coefficient of 1 with the particular factor would have ranked the 34 statements. This idealized Q sort thus represents the distinct, subjective point of view on the topic of health care priorities expressed by that factor. Next, the best factor solution was identified based on the statistical features of each factor solution, and the interpretability of the factors.

Three statistical features of interest were inspected: (i) the number of $Q$ sorts uniquely associated with each factor, with a minimum of two non-confounded $Q$ sorts required to identify a factor as a shared viewpoint; (ii) the factor correlations within a factor solution, with lower correlations between factors from the same solution indicating more distinction in content, which facilitates clear interpretation; and (iii) the factor correlations between factor solutions, with higher correlations between factors from different solutions indicating similarity in content, which facilitates comparison of (shifts in) factor content across solutions. For the interpretation of a factor the idealised $\mathrm{Q}$ sort for that factor was laid out (using the sorting grid; Figure 1) and inspected. Although all the statements are considered in relation to each other, particular focus is on the characterising and distinguishing statements for the factor. The characterising statements (i.e., those with a rank score of -4, $3,+3$ or +4 in the idealised $Q$-sort) provide first insight in the content of the factor, as these are the statements that this point of view is least/most in agreement with. The distinguishing statements (i.e., those with a score in the idealised Q-sort of that factor that is 
statistically significantly different $(p<.05)$ from their score in all other factors) are important to identify and highlight essential differences between points of view. Next, the written and verbal comments that respondents provided while completing their $Q$ sort were used to aid and supplement the interpretation of the view represented by the factor. For each factor, only the comments of respondents who were uniquely associated with that factor were used. Finally, attention was also paid to consensus statements (for which scores were not statistically significantly $(p<.05)$ different between any pair of factors), which provide information about issues all factors are in (dis)agreement with.

Finally, to examine whether the findings from the pooled data across countries potentially also existed within countries, we conducted correlation analysis between the results presented here and those found in individual country level analyses (not presented here; between two and four factors/viewpoints per country, available in EuroVaQ project report: Donaldson et al., 2010).

\section{Ethics}

At the time of the study the PI was based at Newcastle University in England and the project met the requirements of that University's Faculty of Medicine Ethics committee.

\section{Results}

A total of 329 members of the general public across the ten countries of study participated in a Q sort interview: 82 in-person, 247 online. A number of online respondents $(33 ; 10.0 \%)$ 
were excluded from the sample because they did not spend sufficient time on the exercise to provide meaningful responses; no differences in socio-demographics were observed between in- and excluded respondents. Two in-person respondents (0.6\%) were excluded because they appeared not to comprehend the exercise, despite detailed and repeated instruction by the interviewer (evident from difficulty conducting the $Q$ sort and contradictions between the placement of statements and the explanation provided by the participant). As a result, 294 useful responses remained for analysis. Mean age was 40.5 (range $17-86 ; 24.8 \%$ aged 18 to $25,61.2 \%$ aged 25 to $65,13.9 \%$ aged 65 and older), $58.5 \%$ was female and $52.0 \%$ had children. Therefore, elderly and male respondents were underrepresented in this sample. In addition, the sample was fairly well-educated (i.e. $42 \%$ was higher educated) and healthy (i.e. mean score of 8.1 on a VAS ranging from 0 ['worst imaginable health state'] to 10 ['best imaginable health state'] and 9.9\% with a score lower than 6).

Inspection of the statistical features of the factor solutions first of all showed that the maximum solution the data supported consisted of five factors, each defined by at least two non-confounded Q sorts. Furthermore, the factor correlations between solutions (see Figure 2) showed that factor 1 of the five-factor solution remained stable between the two- and five-factor solutions ( $2 / 1$ vs. $5 / 1, \rho=0.95)$, indicating that these factors represent the same point of view. The same was the case for factor 5 of the five factor solution $(2 / 2 \mathrm{vs} .5 / 5$, $\rho=0.93)$ and for factor 4 between the three- and five-factor solutions $(3 / 2$ vs. $5 / 4, \rho=0.89)$. In other words, factors $3 / 1,3 / 2$ and $3 / 3$ (as in Figure 2) hardly change in content when additional factors are extracted in the four- and five-factor solutions. If these three factors 
are interpretable, the next question is whether factor $4 / 2$ makes the four-factor solution more interesting than the three-factor solution, and/or factors $5 / 2$ and $5 / 3$ do so for the five-factor solution.

Next, the idealised $Q$ sorts representing the factors generated by three-, four- and fivefactor solutions were examined. The five-factor solution was selected because it had a clearly interpretable account for each factor, which was consistent with the written and verbal comments which the respondents identifying the factors provided while completing the $Q$ sort. The five factors together explained $52 \%$ of the total variance in the $Q$ sorts. Table 1 presents the idealised $Q$ sorts for each of the five factors, highlighting the salient positive and negative statements. Each factor is described in more detail in the following five subsections.

[Figure 2 about here]

[Table 1 about here]

\section{Viewpoint I: "Egalitarianism, entitlement and equality of access"}

The first of the five factors is a viewpoint which is relatively familiar from the health economics and other literatures and could be described as an egalitarian view on health care priority setting. In this viewpoint, health care is regarded as a basic right and the focus of this factor is on solidarity, entitlement and equality of access to health services.

The two most important statements (\#4, \#29 with score +4 ; Table 1) emphasise that personal characteristics should be of no relevance to the distribution of health care 
resources. This egalitarian position is reinforced by an opposition, in this viewpoint, to the purchase of priority treatment by those with sufficient resources (\#24 is placed at +3 ), even if doing so would not affect others. In all other viewpoints there is no opposition, or at least there is ambivalence towards this issue. The positive placing of statement \#24 is, therefore, significant in the interpretation of this factor and strengthens the interpretation of this as a viewpoint based on principles of equality.

It is consistent that statements \#3 and \#5 are the most rejected statements in factor 1. This rejection of priority based on income, perhaps more unexpectedly, also applies to people from lower income groups $(\# 16,-3)$. Respondents who are associated with this point of view describe a health care system in which treatment priorities are strictly separated from issues of contribution. Having a partner or dependents $(\# 7,-3 ; \# 31,-1)$, personal responsibility for health and lifestyle $(\# 21,+2 ; \# 25,-2)$ and past use of health services (\#34, +2) are also not considered relevant for priority setting either in this viewpoint. Some attention is given to medical need in setting priorities $(\# 29,+4)$, which can be interpreted as a form of horizontal equity (defined as "equal treatment for equal need"). Doctors should be the ones to judge this $(\# 12,+3)$, but overall there is support that saving life $(\# 8,+2 ; \# 17,-3)$ and prevention $(\# 27,+3)$ should matter. It is noteworthy that in this egalitarian viewpoint, relative to the other viewpoints, least weight is put on effectiveness of care $(\# 15,+2 ; \# 19$, +1 ) and that matters of scarcity and opportunity cost are not regarded as important $(\# 6,-2)$.

\section{Viewpoint II: "Severity and the magnitude of health gains"}

The second of the five factors is a viewpoint which focuses on prioritising health care towards patients in greatest need and treatments that will generate the most health 
benefits for all. Hence, the emphasis is on health-related needs of patients and not on their personal, social or economic characteristics $(\# 29,+4 ; \# 4,+4)$. 'Need' in this factor is related to severity of illness and encompasses concerns about worsening health $(\# 18,+2)$ and illnesses that are life threatening (\#8). Past use of health services $(\# 34,+3)$ is least relevant as compared to the other viewpoints, which may relate to the concern with severity; people who have made more use of health services are likely to have poorer health and thus greater need for care. There is also the strongest opposition to prioritising health care on the basis of age $(\# 23,-3 ; \# 14,-1)$ in this view, notably, even if this means younger people would enjoy health benefits over a longer period of time $(\# 26,-4)$. Notwithstanding the focus on severity, maximising health benefits relative to costs from treatment is important in factor 2 and priority is given to those treatments that generate the greatest health gain as well $(\# 15,+3$; $\# 19,+2)$.

As in other factors, no account should be taken of personal contribution to the health service either $(\# 3,-3 ; \# 5,-3)$, nor should a special case be made for those in low income groups (\#16, -3). Despite this, there is no opposition here to privately funded health care and people who are able to pay for their treatment should be allowed to do so (\#24, -2). Culpability (\#21, +2; \#25, -2) has no role to play in this view.

\section{Viewpoint III: "Fair innings, young people and maximising health benefits"}

The most distinct feature of the third viewpoint is the relevance of patients' age in priority setting. This preference for treating the young clearly distinguishes this viewpoint from the four other viewpoints, in particular viewpoint II. Three statements in the top nine ranked statements are significantly distinguishing statements, which deal with prioritising younger 
over older patients $(\# 14,+3 ; \# 23,+3 ; \# 26,+2)$. Consistent with this position, statement \#4, generally accepted in other factors, is rejected since priorities set on the basis of age are evaluated positively in this view. There are two reasons for privileging the young, both of which are regarded as legitimate. Statements \#14 and \#23 represent the 'fair innings' argument, whilst statement \#26 relates priorities for young people to 'prospective health', a health maximising argument which emerges more generally in this factor $(\# 15,+4 ; \# 19,+2$; $\# 32,+3)$. Noteworthy is that in this 'ageist' viewpoint, relative to other factors, lower priority is given to prevention $(\# 27,0)$.

Furthermore, because investment should be directed towards those interventions that generate the most benefit, treatments should not be provided on a first come first served basis (\#28 is rejected strongly at-4 - and only in this factor) nor should treatment priorities depend on patients' economic circumstances (\#16, -2; \#5, -3), financial contributions to the health service $(\# 3, \# 5)$ or ability to purchase private health care $(\# 24,-2)$.

\section{Viewpoint IV: "The intrinsic value of life and healthy living"}

The value of life and the personal responsibility for taking care of one's own health are prominent principles underlying this fourth viewpoint. It permits priority setting based on a number of personal characteristics. This is a considerable departure from viewpoints I and II which stipulated that everyone is equally worthy of treatment. An important distinction made in this view is that individuals' lifestyle choices are regarded relevant to the issue of

priority setting, apparent from the agreement with statement \#25 (+3) and the strong rejection of statement \#21 (-4). From respondents' explanations, this importance of personal 
responsibility for health appears to be linked to a more fundamental belief that life is intrinsically valuable.

The size of the health gain from treatment is important in this view as it is in all other viewpoints $(\# 15,+3 ; \# 19,+3)$. Prevention is also ranked highly $(\# 27,+4)$, both in relation to individual lifestyle and population health. Moreover, high value is attached to preserving life, even when quality of life is poor $(\# 17,-2)$ and to people with low quality of life, even when gains from treatment are small $(\# 11,-3)$. Rescuing people from certain death should take priority over all other kinds of health care $(\# 8,+4)$. The belief in the inherent value of life is not connected to a strong priority for younger people, since statements \#14, \#23 and \#26 achieve little agreement (positioned at $0,-1$ and -1 respectively).

Finally, it is notable that there is a higher preference in this viewpoint than in other factors for prioritising parents with dependent children $(\# 31,+2)$, and priority for people with a partner $(\# 7,0)$ is not strongly rejected. In addition, consideration of issues relating to labour productivity and financial contribution to the health care sector are not strongly opposed in this view $(\# 3,-2 ; \# 5,0 ; \# 24,-4)$, and these three statements are distinguishing for this viewpoint.

\section{Viewpoint V: "Quality of life is more important than simply staying alive"}

Quality of life is the key issue in this final, fifth view. Statement $\# 17(+4)$ is the most important positive statement in this factor and distinguishes it from all other factors. Statements \#8 (+4) and \#33 (-4), both of which suggest that life-saving treatments are the most important, are firmly rejected, and the placement of these statements also significantly distinguishes this viewpoint from all others. In conjunction, statements \#8, \#17 and \#33 
reveal a belief that quality rather than length of life should be the aim of health services. This emphasis on quality of life relates specifically to prognosis as a result of treatment and not simply the prioritising of patients who are severely ill and where little (or less) can be done to improve quality of life $(\# 11,-2 ; \# 18,0)$. In this viewpoint, the focus should be on treatments that are effective $(\# 19,+3)$, efficient $(\# 15,+3)$ and restore health to an acceptable level $(\# 22,+2)$.

There is some support for the role of doctors in priority setting $(\# 12,+2)$ and prevention of ill health is important in this view, as in others $(\# 27,+3)$, perhaps seen by respondents in terms of personal responsibility $(\# 21,-2 ; \# 25,+1)$.

In line with most other views, personal financial contribution and economic productivity should be irrelevant to health care decision making $(\# 3,-4 ; \# 5,-3)$.

\section{Are European factors supported by country level results?}

Our analysis pools data from $Q$ sorts collected in multiple countries because our primary interest was in shared views across those countries. A natural question following our analysis is whether the views presented here exist only across countries or also 'exist' within countries - in other words, are recognisable in individual countries.

Correlations between each of the points of view found at the country level with at least one of the five European points of view ranged between a moderate 0.60 and an excellent 0.97 (with 4 of the 29 national viewpoints with correlations in the range $0.60-0.70$, 11 in $0.70-0.80$, another 11 in $0.80-0.90$ and $3>0.90$ ). This indicates that the majority of the country level views were well-represented in the five European views, and that none of the 
country-level views that we identified remained unrepresented in the factors generated by the analysis of the pooled data.

Conversely, taking each of the European points of view and examining the range of correlation coefficients for each of the 29 country level points of view we observe correlations between 0.72-0.91 for viewpoint I, 0.71-0.91 for viewpoint II, 0.39-0.89 for viewpoint III, 0.44-0.97 for viewpoint IV and 0.44-0.88 for viewpoint V, indicating good to excellent representation of viewpoints I and II in all 10 countries, but varying representation for the other three viewpoints.

In other words, the five points of view presented in this paper appear to be present across as well as within the 10 participating countries.

\section{Discussion}

This study represents a significant, novel piece of work eliciting societal views regarding the appropriate principles for prioritising health care resources shared across ten countries. This is the first example of such a study in an international context. Applying Q methodology, 294 members of the public in 10 different countries completed card sorts, which overall resulted in five distinct viewpoints about how health and health care should be prioritised. Here, these data were pooled for a European level analysis, and comparisons were drawn with the 10 individual country level analyses.

Our main finding is that there is a plurality of societal views about prioritising health care, related to notions of (outcome and procedural) fairness and the aim of the health care sector. In an era in which health care decision making is becoming more and more important 
and publicly debated, insights into existing views on how health care decisions ought to be made according the general public is highly relevant. Given the normative nature of this topic (Williams, 1988b) and the often heated debates when prioritizations are made explicit, this result needs not be considered surprising. In that sense, it is perhaps more surprising that 'only' five viewpoints were found in this sample from the general public across ten European countries, with their different cultural backgrounds and health care systems (Hofstede, 1995). These viewpoints seem to reflect broader ethical notions like fairness, solidarity and equity, which may differ between countries, but may well be similar between subgroupings from different countries. Many statements included in the $Q$ set refer to issues of life and death and, for some respondents, may touch on fundamental political and religious beliefs. For instance, the egalitarian viewpoint (I) seems to be consistent with a somewhat left-wing view of the welfare state, concerned with equality and solidarity. The inherent value of life viewpoint (IV) may be connected with religious beliefs or healthy lifestyle views. The focus on quality of life and 'a life worth living' (V) may be perceived to reflect more liberal views. Moreover, not only are there differences between the viewpoints in terms of the importance attached to outcomes (e.g., in the young or the old), but also regarding the process (e.g., first come first served) and who should decide (e.g., the role of doctors).

These findings are important for several reasons. First of all, it is important to understand the nature and content of existing viewpoints, as they will indicate the likely agreement with or opposition to specific health care policies. Broadly speaking, and in line with pleas by Alan Williams (1988b), the viewpoints observed in this study appear to give little support to 'libertarian' policies, and considerable support to 'egalitarian' ones. 
Secondly, it is important to understand the diversity in viewpoints. It is unlikely that there is one decision rule that will satisfy all equity considerations and viewpoints simultaneously. It is also questionable whether the search for equity weights (to adjust the outcomes for distributional preferences in society) or flexible thresholds (to provide each equity-subgroup with its relevant comparator) will do justice to the complex nature and plurality of the viewpoints described. Hence, our results imply that the process of decision making is essential. Ensuring that the plurality of viewpoints is adequately reflected, if not in the outcome of the decision then at least in a more deliberative decision making process, becomes an important challenge (see also Linley \& Hughes, 2013; Wiseman et al., 2003; Anand \& Wailoo, 2000; Klein, 1993). Given the diverse and in some respects contradictory principles for priority setting put forward in these views, such a process will most likely not lead to an outcome which aligns with all prevalent views in society. But it ensures attention is given to each of these views before the final decision is taken, which may be considered important in the legitimisation of such decisions (in line with notions like accountability for reasonableness; Daniels, 2000).

As called for by Williams (1988: “...what should be happening is a systematic effort to bring home to the citizen-taxpayers the nature of the dilemmas that have to be faced, the options available and their likely consequences, and some consideration of the principles which should inform policy", pp. 567), some countries use a form of public consultation or stakeholder engagement in an attempt to involve societal viewpoints in health care decision making processes. Examples are NICE's citizens' councils in the UK (Littlejohns and Rawlins 2009), the health parliament in Israel (Guttman et al., 2008), and representation in appraisal committees in Germany and the Netherlands (Gagnon et al., 2011). Some experiences with 
citizens' juries have also been reported (Menon \& Stafinski, 2008; Mooney \& Blackwell, 2004). This, however, will only do justice to the diversity of existing viewpoints if the people on those panels or committees indeed (are able to) reflect these viewpoints. One may argue, therefore, that it is important that such bodies select people on the basis of being representative of the views in society rather than in assuming different perspectives are represented on the basis of socio-demographic, professional background or healthcharacteristics. The latter obviously does not ensure adequate representation of the range of viewpoints. Q methodology has been shown to be a useful method for selection of people based on their viewpoint (Cuppen et al., 2013, 2010; Brown, 2006; Van Eeten, 2001).

It is important to highlight some limitations and features of our study. First of all, this is a Q methodological study, which implies that it is 'only' concerned with finding the principal viewpoints about this topic in society. It does not address the question of how common such viewpoints are in society. Determining the prevalence of the different viewpoints requires additional research. Methods to explore $Q$ factor membership in a large representative survey sample are available (Baker et al., 2010). Secondly, we presented European viewpoints here, based on pooled data from ten countries. Analysis of the individual country data (not presented here) showed that a similar plurality of views among the public can be expected at national levels. It also revealed that these five European views were not observed in each and every participating country. This may relate to differences in sampling or social value orientations, for example, and it would therefore be interesting to replicate this study at national levels with larger and more carefully selected samples and to explore these differences between countries in more detail in future research. Third, while we have placed much emphasis on carefully and thoughtfully developing and pilot-testing the $Q$ set, 
i.e. the statements used in the card sort, it must be noted that when dealing with a broad topic like health care prioritization, other choices could have been made, possibly affecting outcomes. The same holds for the sampling frame for participants in the study. In each country we have managed to recruit more than sufficient participants for each of the subgroups defined by the sampling frame, and there were no indications that important topics or viewpoints were missed. In the pilot study participants were specifically asked whether topics of their concern were missing in the Q-set, and in the main study participants were requested to comment on the statements. From this, we have no indication that important issues were omitted.

To conclude, this research has identified five distinct viewpoints among the public in ten countries regarding principles for health care priority setting. Given the increasing pressure on health care budgets and the need to prioritise within health care systems it is important to have knowledge regarding existing viewpoints on that topic in societies, and their distribution. Only with such knowledge can health policies reflecting, or at least respecting the views of the public be purposely devised. This research hopes to contribute to that aim. 


\section{Acknowledgement}

The European Value of a QALY (EuroVaQ) project was funded by the European Commission, $6^{\text {th }}$ Framework Programme under grant agreement $n^{\circ} 044172$. All the views expressed here are those of the authors. None of the authors report any conflicts of interest.

We thank the other members of the EuroVaQ team who contributed to the work presented here: Sue Bell, Michael Jones-Lee, John Wildman (Newcastle University); Emily Lancsar (Monash University, Melbourne \& Newcastle University); Angela Robinson, Philomena Bacon (University of East Anglia); Jan Abel Olsen (University of Tromso); Dorte Gyrd-Hansen, Trine Kjaer, Mickael Beck, Jytte Seested Nielsen (University of Southern Denmark); Ulf Persson, Annika Bergman (Swedish Institute of Health Economics, Lund); Christel Protière, Jean Paul Moatti (INSERM, U-912, Université Aix-Marseille); Stephane Luchini (GREQAM, Centre National de la Recherche Scientifique, Marseille); Jose Luis Pinto Prades (Pablo de Olavide University, Seville); Awad Mataria, Rana Khatib, Yara Jaralla (Birzeit University, OPT); Roman Topór-Madry, Adam Kozierkiewicz, Darek Poznanski, Ewa Kocot (Jagiellonian University Medical College, Krakow, Poland); László Gulácsi, Márta Péntek (Corvinus University Budapest); Samer Kharroubi, Andrea Manca (University of York); Phil Shackley (University of Sheffield). We are particularly grateful to Mark Pennington (London School of Hygiene \& Tropical Medicine \& Newcastle University) for helpful comments on an earlier version of this paper. 


\section{References}

Anand, P., Wailoo, A. (2000). Utilities versus Rights to Publicly Provided Goods: Arguments and Evidence from Health Care Rationing. Economica, 67, 543-77.

Baker, R., Bateman, I., Donaldson, C., et al. (2010). Weighting and valuing quality-adjusted life-years using stated preference methods: preliminary results from the Social Value of a QALY Project. Health Technology Assessment, 14, :1-162.

Baker, R., van Exel, J., Mason, H., Stricklin, M. (2010). Connecting Q \& surveys: a test of three methods to explore factor membership in a large sample. Operant Subjectivity, 34, 38-58.

Baker, R. (2006). Economic rationality and health and lifestyle choices for people with diabetes. Social Science \& Medicine, 63, 2341-2353.

Baker, R., Wildman, J., Mason, H., Donaldson, C. (2014). Q-ing for health: an integrated mixed-methods approach to eliciting the public's views on health care resource allocation. Health Economics, 23, 283-297.

Bobinac, A., van Exel, N.J.A., Rutten, F.F.H., Brouwer, W.B.F. (2012). Inquiry into the relationship between the equity weights and the value of a QALY. Value in Health, 15, 11191126.

Boot, C.R.L., van Exel, N.J.A., van der Gulden, J.W.J. (2009). "My Lung Disease Won't Go Away, it's There to Stay": Profiles of Adaptation to Functional Limitations in Workers with Asthma and COPD. Journal of Occupational Rehabilitation, 19, 284-292. 
Brouwer, W.B., Schut, F.T. (1999). Priority care for employees: a blessing in disguise? Health Economics, 8, 65-73.

Brouwer, W.B.F., van Exel, N.J.A., Baker, R., Donaldson, C. (2008), The new myth: The social value of the QALY. PharmacoEconomics, 26, 1-4.

Brown, S.R. (1980). Political Subjectivity. Applications of Q Methodology in Political Science. New Haven: Yale University Press.

Brown, S.R. (2006). Match Made in Heaven: A Marginalized Methodology for Studying the Marginalized. Quality \& Quantity, 40, 361-382.

Brown, S.R., Danielson, S., van Exel, J. (2014). Overly ambitious critics and the Medici Effect: a reply to Kampen and Tamás. Quality \& Quantity, in press [doi: http://link.springer.com/article/10.1007\%2Fs11135-014-0007-x]

Buljac, M., van Wijngaarden, J.D.H., van Wijk, K.P., van Exel, N.J.A. (2010). Perceptions of team workers in youth care of what makes teamwork effective. Health \& Social Care in the Community, 19, 307-316.

Buxton, M.J., Chambers, J.D. (2011). What values do the public want their health care systems to use in evaluating technologies? European Journal of Health Economics, 12, 285288.

College voor Zorgverzekeringen. (2006). Pakketbeheer in de praktijk [in Dutch]. Diemen.

Cramm, J.M., Finkenflügel, H., Møller, V., van Exel, N.J.A. (2010). Patient views on determinants of adherence with tuberculosis treatment in the Eastern Cape, South Africa: 
An application of Q-methodology. The Patient: Patient-Centered Outcomes Research, 3, 159172.

Cuppen, E., Breukers, S., Hisschemöller, M., Bergsma, E. (2010). Q Methodology to select participants for a stakeholder dialogue on energy options from biomass in the Netherlands. Ecological Economics, 69, 579-591.

Cuppen, E. (2013). Q Methodology to Support the Design and Evaluation of Stakeholder Dialogue. Operant Subjectivity, 36, 135-161.

Daniels, N. (2000). Accountability for reasonableness. BMJ, 321: 1300-1301.

De Graaf, G., van Exel, J. (2009). Using Q-methodology in Administrative Ethics. Public Integrity, $11,63-78$

Dolan, P., Shaw, R., Tsuchiya, A., Williams, A. (2005). QALY maximisation and people's preferences: a methodological review of the literature. Health Economics, 14, 197-208.

Donabedian, A. (1971). Social Responsibility for Personal Health Services: An Examination of Basic Values. Inquiry, 8, 3-19.

Donaldson, C., Atkinson, A., Bond, J., Wright, K. (1988). Should QALYs be programme specific. Journal of Health Economics, 7, 239-257.

Donaldson, C., Gerard, K. (1989). Countering moral hazard in public and private health care systems: a review of recent evidence. Journal of Social Policy, 18, 235-251. 
Donaldson, C., Baker, R., et al. (2010). European Value of a Quality Adjusted Life Year. Final Publishable Report of the EUROVAQ project (SP5A-CT-2007-044172). Retrieved from: http://research.ncl.ac.uk/eurovaq/.

Donaldson, C., Baker, R., Mason, H., et al. (2011). The social value of a QALY: raising the bar or barring the raise? BMC Health Services Research, 11, 8.

Eccleston, C., Willams, A.C.D., Stainton Rogers, W. (1997). Patients' and professionals' understandings of the causes of chronic pain: blame, responsibility and identity protection. Social Science \& Medicine, 45, 699-709.

Gagnon, M.P., Desmartis, M., Lepage-Savary, D., et al. (2011). Introducing patients' and the public's perspectives to health technology assessment: A systematic review of international experiences. International Journal of Technology Assessment in Health Care, 27, 31-42.

Gerard, K., Mooney, G. (1993). QALY league tables: Handle with care. Health Economics, 2, 59-64.

Goldberg, L.R. (2006). Doing it all Bass-Ackwards: The development of hierarchical factor structures from the top down. Journal of Research in Personality, 40, 347-358.

Greiner, W., von der Schulenburg, J.M.. (2010). HTA in Germany: very special and specific. The European Journal of Health Economics, 11, 1-3.

Guttman, N., Shalev, C., Kaplan, G., et al. (2008). What should be given a priority - costly medications for relatively few people or inexpensive ones for many? The Health Parliament public consultation initiative in Israel. Health Expectations, 11, 177-88. 
Hofstede, G. (1995). Insurance as a product of national values. Geneva Papers on Risk and Insurance, 77, 423-29.

Klein, R. (1993). Dimensions of rationing: who should do what? BMJ, 307, 309-311.

Kline, P. (1994). An easy guide to factor analysis. New York: Routledge.

Kraijo, H., Brouwer, W., de Leeuw, R., et al. (2012). Coping with caring: Profiles of caregiving by informal carers living with a loved one who has dementia. Dementia, 11, 113-130.

Lancsar, E., Wildman, J., Donaldson, C., et al. (2011). Deriving distributional weights for QALYs through discrete choice experiments. Journal of Health Economics, 30, 466-478.

Linley, W.G., Hughes, D.A. (2013). Societal Views On Nice, Cancer Drugs Fund And ValueBased Pricing Criteria For Prioritising Medicines: A Cross-Sectional Survey Of 4118 Adults In Great Britain. Health Economics, 22, 948-964.

Littlejohns, P., Rawlins, M. (eds). (2009). Patients, the public and priorities in healthcare. Oxford: Radcliffe Publishing.

Litva, A., Coast, J., Donovan, J., et al. (2002). 'The public is too subjective': public involvement at different levels of health-care decision making. Social Science \& Medicine, 54, 1825-1837.

Lobo, V.M., Fisher, A., Baumann, A., Akhtar-Danesh, N. (2012). Effective retention strategies for midcareer critical care nurses: a Q-method study. Nursing Research, 61, 300-308.

Longson, C., Littlejohns, P. (2009). Update Report on the Application of the 'End-Of-Life' Supplementary Advice in Health Technology Appraisals. London: National Institute for Health and Clinical Excellence. 
McKeown, B.F., Thomas, D.B. (2013). Q methodology. (Quantitative Applications in the Social Sciences series, volume 66, 2nd ed). Thousand Oaks, CA: Sage.

Menon, D., Stafinski, T. (2008). Engaging the public in priority-setting for health technology assessment: findings from a citizens' jury. Health Expectations, 11, 282-293.

Mooney, G.H., Blackwell, S.H. (2004). Whose health service is it anyway? Community values in healthcare. Medical Journal of Australia, 180, 76-78.

National Institute for Health and Clinical Excellence. (2009). Appraising life-extending, end of life treatments. London.

Nord, E. (2005). Concerns for the worse off: fair innings versus severity. Social Science \& Medicine, 60, 257-63.

Pennington, M., Baker, R., Brouwer, W., et al. (2013). Comparing WTP values of different types of QALY gain elicited from the general public. Health Economics, in press [http://dx.doi.org/10.1002/hec.3018].

Risdon, A.., Eccleston, G., McCracken, L. (2003). How can we learn to live with pain? A Qmethodological analysis of the diverse understandings of acceptance of chronic pain. Social Science \& Medicine, 56, 375-86.

Robinson, A., Gyrd-Hansen, D., Bacon, P., et al.(2013). Estimating a WTP-based value of a QALY: the 'chained' approach. Social Science \& Medicine, in press [http://dx.doi.org/10.1016/j.socscimed.2013.05.013]. 
Schmolck, P., Atkinson, J. (2002). PQMethod software and manual 2.11. Available from: http://www.Irz.de/ schmolck/qmethod.

Schwappach, D.L.B. (2002). Resource allocation, social values and the QALY: a review of the debate and the empirical evidence. Health Expectations, 5, 210-222.

Scottish Medicines Consortium NS. (2010). Guidance to the Manufacturers for Completion of New Product Assessment Form (NPAF).

Smith, R.D., Richardson, J. (2005). Can we estimate the 'social' value of a QALY?: Four core issues to resolve. Health Policy, 74, 77-84.

Stenner, P.H.D., Cooper, D., Skevington, S.M. (2003). Putting the Q-into quality of life; The identification of subjective constructions of health-related quality of life using Qmethodology. Social Science \& Medicine, 57, 2161-2172.

Stephenson, W. (1935). Correlating persons instead of tests. Character and Personality, 4, $17-24$.

Tielen, M., van Staa, A., Jedeloo, S., et al. (2008). Q-methodology to identify young adult renal transplant recipients at risk for non-adherence. Transplantation, 85, 700-706.

Tsuchiya, A., Dolan, P. (2005). The QALY model and individual preferences for health states and health profiles over time: a systematic review of the literature. Medical Decision Making, 25, 460-467. 
Van de Wetering, E.J., Stolk, E.A., van Exel, N.J., Brouwer, W.B. (2013). Balancing equity and efficiency in the Dutch basic benefits package using the principle of proportional shortfall. European Journal of Health Economics, 14, 107-115.

Van Eeten, M.J.G. (2001). Recasting Intractable Policy Issues: The Wider Implications of The Netherlands Civil Aviation Controversy. Journal of Policy Analysis and Management, 20, 391414.

Van Exel, N.J.A., de Graaf, G., Brouwer, W.B.F. (2006). "Everyone dies, so you might as well have fun!" Attitudes of Dutch youths about their health lifestyle. Social Science \& Medicine, 63, 2628-2639.

Vermaire, J.H., Hoogstraten, J., van Loveren, C., et al. (2010). Attitudes toward oral health among parents of six-year-old children at risk of developing caries. Community Dentistry and Oral Epidemiology, 38, 507-520.

Wallenburg, I., van Exel, N.J.A., Stolk, E., et al. (2010). Between Trust and Accountability: Different Perspectives on the Modernization of Postgraduate Medical Training in the Netherlands. Academic Medicine, 85, 1082-1090.

Watts, S., Stenner, P. (2012). Doing Q Methodological Research: Theory, Method and Interpretation. London: Sage.

Weinstein, M.C. (1988). A QALY Is a QALY Is a QALY - Or Is It? Journal of Health Economics, 7, 289-290.

Williams, A. (1988a). Ethics and Efficiency in the Provision of Health Care. Royal Institute of Philosophy Lecture Series, 23, 111-26. 
Williams, A. (1988b). Priority setting in Public and Private Health Care. Journal of Health Economics, 7, 173-183.

Williams, A. (1997). Intergenerational equity: an exploration of the 'fair innings' argument. Health Economics, 6, 117-132.

Williams, A. (1998). Medicine, Economics, Ethics and The NHS: A Clash of Cultures? Health Economics, 7, 565-568.

Wiseman, V., Mooney, G., Berry, G., Tang, K.C. (2003). Involving the general public in priority setting: experiences from Australia. Social Science \& Medicine, 56, 1001-1012. 


\section{Table 1 Statement rank scores general public}

\section{Statement}

Point of view

\section{If two groups of patients can benefit from a treatment equally and}

1 If two groups of patients can benefit from a treatment equally and group A's health is fairly good and group B's health is poor, group B deserves priority.

2 If one treatment results in one life year gained for certain and another in a $50 \%$ chance of gaining two life years, priority should be given to the first type of treatment.

3 People who have contributed more (e.g. through premiums or taxes) to the health care system should be treated with priority over people who have contributed less.

4 Patient characteristics like age, gender or income should play no role in prioritising between people.

5 People who are in paid work and so contribute financially to society should be prioritised over people who do not work.

6 If a treatment adds one month to the life of a patient and costs 7.500 Euros, one should consider whether the money could have been better spent on other health care.

7 If two patients are waiting for a transplant organ, one with partner and the other single but otherwise identical, the first organ to become available should go the patient with partner.

8 Rescuing people from a certain death should take priority over all other kinds of health care.

9 Treatment of illnesses that put the highest burden on patients' families should receive higher priority.

10 A treatment which benefits patients in the short-term should have priority over a treatment with similar benefits for patients in the future.

11 Priority should be given to people whose quality of life is low over those whose quality of life is moderate, even if treatment can only improve their quality of life by a small amount.

12 Doctors should be the ones to judge which patients get priority on the basis of their medical expertise.

13 People who depend heavily on members of their family or neighbours for care should be treated with priority.

14 Adding one year to the end of life for someone who will otherwise die at age 30 is more important than adding one year to the life of someone who otherwise would die at age 80 .

15 When having to choose between two treatments that both cost the same, funding should be given to the treatment that results in the biggest health gain.

16 In general, if people from different income groups are suffering from the same condition, people from low income groups should be given priority.

17 There is no sense in saving lives if the quality of those lives will be really bad.

\begin{tabular}{|c|c|c|c|c|}
\hline I & II & III & IV & V \\
\hline$+1^{*}$ & +1 & +2 & -1 & -1 \\
\hline 0 & 0 & 0 & 0 & -1 \\
\hline-4 & -4 & -4 & $-2 *$ & -4 \\
\hline$+4^{*}$ & $+4^{*}$ & $-2^{*}$ & $+1^{*}$ & $+2 *$ \\
\hline-4 & -3 & -3 & 0* & -3 \\
\hline$-2^{*}$ & 0 & +1 & $0^{*}$ & +1 \\
\hline-3 & -2 & -2 & 0* & -2 \\
\hline$+2^{*}$ & $+3^{*}$ & $+1^{*}$ & $+4^{*}$ & $-3^{*}$ \\
\hline+1 & 0 & -1 & +1 & 0 \\
\hline 0 & +1 & -1 & 0 & 0 \\
\hline-1 & 0 & -1 & $-3^{*}$ & $-2^{*}$ \\
\hline+3 & +1 & 0 & +2 & +2 \\
\hline 0 & +1 & 0 & -1 & 0 \\
\hline 0 & $-1^{*}$ & $+3^{*}$ & 0 & $+1^{*}$ \\
\hline$+2^{*}$ & +3 & +4 & +3 & +3 \\
\hline-3 & -3 & -2 & -3 & -2 \\
\hline-3 & -1 & -1 & -2 & $+4^{*}$ \\
\hline
\end{tabular}




\begin{tabular}{|c|c|c|c|c|c|c|}
\hline \multicolumn{2}{|c|}{ Statement } & \multicolumn{5}{|c|}{ Point of view } \\
\hline & & \multirow{2}{*}{$\begin{array}{c} \\
+1\end{array}$} & \multirow{2}{*}{$\frac{\text { II }}{+2 *}$} & \multirow{2}{*}{$\begin{array}{l}\text { III } \\
+1\end{array}$} & \multirow{2}{*}{ IV } & \multirow{2}{*}{$\begin{array}{l} \\
\end{array}$} \\
\hline 18 & $\begin{array}{l}\text { If two people have the same current condition but the health of one of } \\
\text { the two is worsening while that of the other is stable, the former } \\
\text { should be treated with priority. }\end{array}$ & & & & & \\
\hline 19 & $\begin{array}{l}\text { Priority should be given to those treatments that generate the most } \\
\text { health. }\end{array}$ & $+1 *$ & +2 & +2 & +3 & +3 \\
\hline 20 & $\begin{array}{l}\text { It is more important to extend one person's life by one year than to } \\
\text { extend } 12 \text { people's lives by one month. }\end{array}$ & -2 & -1 & $+1 *$ & -1 & -1 \\
\hline 21 & $\begin{array}{l}\text { Whether an illness is the result of an unhealthy lifestyle should not be } \\
\text { relevant, everyone is just as worthy of treatment as everyone else. }\end{array}$ & +2 & +2 & +2 & $-4 *$ & $-2^{*}$ \\
\hline 22 & $\begin{array}{l}\text { Priority should be given to treatments that restore health to an } \\
\text { acceptable level, there's no use in improving health when the final } \\
\text { result is still a very poor state of health. }\end{array}$ & +1 & +1 & -1 & +1 & $+2 *$ \\
\hline 23 & $\begin{array}{l}\text { Younger people should be given priority over older people, because } \\
\text { they haven't had their fair share of health yet. }\end{array}$ & -2 & $-3^{*}$ & $+3 *$ & -1 & $0^{*}$ \\
\hline 24 & $\begin{array}{l}\text { People should not be allowed to buy themselves priority treatment, } \\
\text { even if it doesn't affect others negatively. }\end{array}$ & $+3 *$ & -2 & -2 & $-4 *$ & $-1^{*}$ \\
\hline 25 & $\begin{array}{l}\text { People who are in some way responsible for their own illness should } \\
\text { receive lower priority than people who have the same illness simply } \\
\text { due to chance. }\end{array}$ & $-2 *$ & -2 & -3 & $+3^{*}$ & $+1^{*}$ \\
\hline 26 & $\begin{array}{l}\text { Priority should be given to younger people, because they may benefit } \\
\text { from treatment for longer. }\end{array}$ & 0 & $-4^{*}$ & $+2 *$ & -1 & $0^{*}$ \\
\hline 27 & $\begin{array}{l}\text { It is more important to prevent ill health than it is to cure ill health } \\
\text { once it occurs. }\end{array}$ & +3 & $+2 *$ & $0 *$ & +4 & +3 \\
\hline 28 & $\begin{array}{l}\text { For non-emergency treatments where there are waiting lists, patients } \\
\text { in need of care should be treated on a first come first served basis and } \\
\text { not be prioritised in other ways (e.g. the severity of the illness). }\end{array}$ & 0 & 0 & $-4^{*}$ & $-2 *$ & $-1 *$ \\
\hline 29 & $\begin{array}{l}\text { Access to health care should be based on need, not on geographical, } \\
\text { social or economic circumstances. }\end{array}$ & +4 & +4 & +4 & +2 & +4 \\
\hline 30 & $\begin{array}{l}\text { Priority should be given to people with rare diseases, even when these } \\
\text { diseases do not necessarily cause more health damage than more } \\
\text { common ones. }\end{array}$ & $-1^{*}$ & $0 *$ & -3 & -3 & -3 \\
\hline 31 & $\begin{array}{l}\text { Parents with dependent children should be given priority over similar } \\
\text { people without dependents. }\end{array}$ & $-1^{*}$ & $-2 *$ & 0 & $+2^{*}$ & +1 \\
\hline 32 & $\begin{array}{l}\text { People who benefit more from a treatment, because it is more } \\
\text { effective for them, should receive priority over people who benefit } \\
\text { less from this treatment. }\end{array}$ & -1 & -1 & $+3 *$ & +1 & +1 \\
\hline 33 & $\begin{array}{l}\text { It is more important to provide treatments that prolong life than } \\
\text { treatments that improve quality of life. }\end{array}$ & -1 & -1 & $0 *$ & -2 & $-4^{*}$ \\
\hline 34 & $\begin{array}{l}\text { The amount of health care people have had in the past should not } \\
\text { influence access to treatments in the future. }\end{array}$ & +2 & $+3^{*}$ & +1 & +1 & +2 \\
\hline
\end{tabular}

Note: * indicates statement is distinguishing $(p<.05)$. 
Figure 1 Score sheet used for ranking the statements

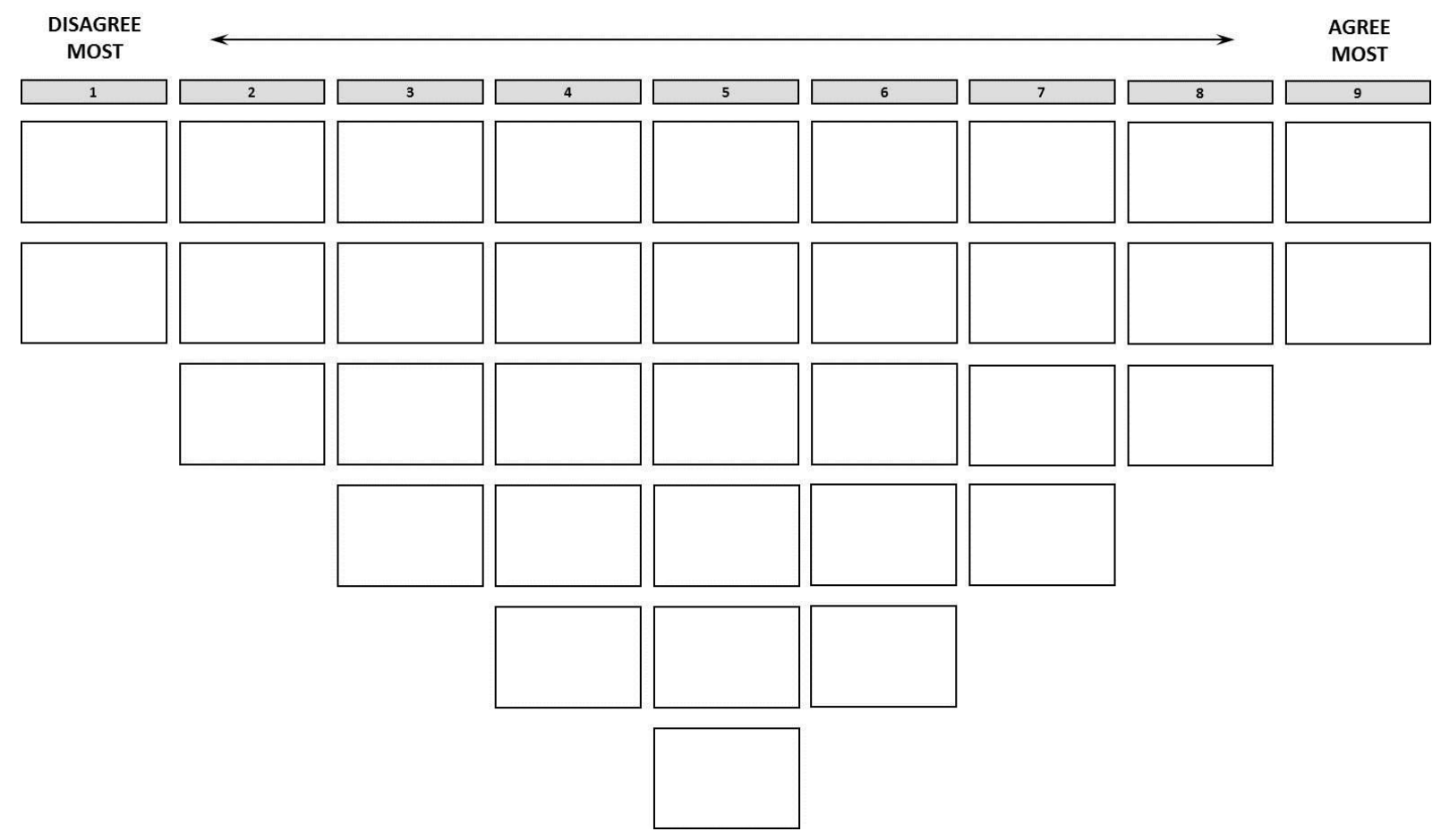


Figure 2 Factor diagram: correlations between factors from different factor solutions

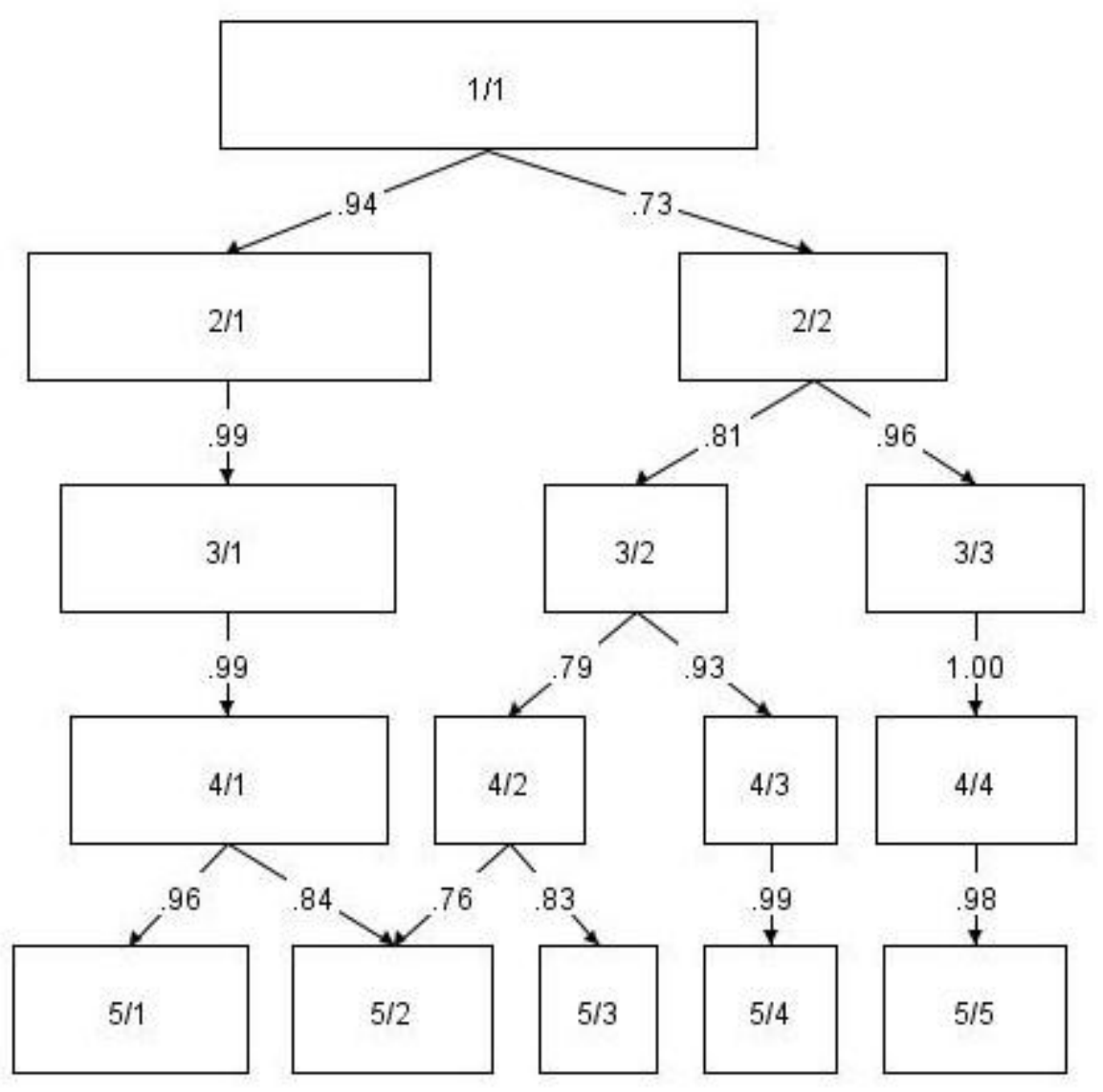

Note:

The factor diagram is a simplified visual representation of the hierarchical factor structure in a data set (Goldberg, 2006). Each row of the factor diagram presents a factor solution, from separate analyses of the data. The boxes in each row represent the factors from that factor solution (i.e. here points of view), the width of these boxes the percentage explained variance. The arrows between boxes indicate the most important correlations ( $\rho>.70$ presented here) between factors in consecutive factor solutions. 


\section{Annex A Theoretical structure for development of statement set resulting from the literature review and corresponding statement numbers in final study set}

\begin{tabular}{|c|c|c|}
\hline Category & Characteristic & Number \\
\hline \multirow[t]{6}{*}{ A. Patient } & 1. Age(ism) / fair innings & $14,23,26$ \\
\hline & 2. Socio-economic status & 16,29 \\
\hline & 3. Prior health consumption / previous health profile & 34 \\
\hline & 4. Payment / contribution & 3,24 \\
\hline & 5. Having dependent adults or children & 7,31 \\
\hline & $\begin{array}{l}\text { 6. Equality / all patients equal (no prioritization on patient } \\
\text { characteristics) }\end{array}$ & 4 \\
\hline \multirow[t]{4}{*}{ B. Illness } & 7. Severity: life threatening vs. mild / stable vs. progressive / chronic & 18 \\
\hline & 8. Rule of rescue / pain / relief intervention & 8 \\
\hline & $\begin{array}{l}\text { 9. Probable cause / culpability: genetic / congenital, bad luck (could } \\
\text { have happened to anyone), avoidable, lifestyle / self-inflicted, } \\
\text { medical negligence / fault of others }\end{array}$ & 21,25 \\
\hline & 10. Rarity & 30 \\
\hline \multirow[t]{2}{*}{ C. Treatment } & 11. Efficiency & 6,15 \\
\hline & 12. Waiting lists / waiting time & 28 \\
\hline \multirow{8}{*}{$\begin{array}{l}\text { D. Health effects of } \\
\text { treatment }\end{array}$} & 13. Size of the effect & 19 \\
\hline & 14. Length vs. quality of life & 17,33 \\
\hline & 15. Certainty of effect occurring & 2 \\
\hline & 16. Distribution of fixed health gains / threshold effect & 10,20 \\
\hline & 17. Start-point before / end-point after treatment & $1,11,22$ \\
\hline & 18. Direction of the effect: health gain / loss avoidance (prevention) & 27 \\
\hline & 19. Proportional shortfall / prospective health / prognostic difference & $\mathrm{N} / \mathrm{A}^{+}$ \\
\hline & $\begin{array}{l}\text { 20. Capacity to benefit: functioning and capabilities regained after } \\
\text { treatment }\end{array}$ & 32 \\
\hline \multirow{3}{*}{$\begin{array}{l}\text { E. Non-health effects } \\
\text { of treatment }\end{array}$} & 21. Social support / family effect / care giving effect & 9,13 \\
\hline & 22. Productivity (work) & 5 \\
\hline & 23. Health effects should be leading & 12 \\
\hline
\end{tabular}

Note: Gender and race were excluded because legislation in many European countries will not allow priority setting using these characteristics. ${ }^{+}$Proportional shortfall was excluded because participants in the pilot studies considered it too complex. 


\section{Annex B Instructions to participants}

These instructions will guide you through the study step by step. Please read through each step completely before you start carrying it out, and please finish each step completely before proceeding to the next one.

This study is about decision making in health care. Even though spending on health varies between countries, all countries are faced with the same problem. That is, the health care budget is never sufficient to do everything that could possibly be done. Because of this, choices must be made about which health services and treatments to provide and, therefore, which not to provide. There is a lot of debate about how decisions like these should be made. We are interested in your views about how health care decisions should be made in your country. The statements on the 34 numbered cards are things people have said about how health care decisions should be made. Later on we will ask you to what extent you agree with these statements.

1. Place the large score sheet in front of you on a table. The 34 numbered cards contain statements about how health care decisions should be made in your country. This study is about people's individual opinions; there are no right or wrong answers. The numbers on the cards (from 1 to 34 ) are to help you to complete the response sheet and apart from that do not have any meaning.

2. Read through the 34 statements carefully and at the same time split them up into three piles: a pile for statements with which you agree (and place them to your right), a pile for statements with which you disagree (and place them to your left), and a pile for statements with which you neither agree nor disagree, do not consider relevant or are unclear to you (and place them in the middle).

3. Take the pile containing the statements you agree with (to your right) and read them through once again. Select the two statements which you AGREE WITH MOST and place them in the extreme right column of the large score sheet, below the " 9 ". It does not matter which of them you place at the top or at the bottom. Next, from the remaining pile select the three statements which you now AGREE WITH MOST and place them in the three spaces below the " 8 ". Proceed until all statements you agree with have been placed on the score sheet.

4. Take the pile containing the statements you disagree with (to your left) and read them through once again. Select the two statements which you DISAGREE WITH MOST and place them in the extreme left column of the score sheet, below the "1". It does not matter which of them you place at the top or at the bottom. Proceed until all statements you disagree with have been placed on the score sheet. 
5. Finally, take the remaining pile and read through these statements once again too. Place the cards in the remaining spaces on the score sheet, just like you feel it should be done.

6. When you have finished placing the cards on the score sheet, read them all through as a final check and change positions if you feel like it.

7. When you are completely ready, please copy the numbers on the cards onto the response sheet, exactly like they are on the large score sheet.

8. Please complete the remaining questions on the response sheet. 